\title{
Rat-pup killing and maternal behavior in male Long-Evans rats: Prenatal stimulation and postnatal testosterone
}

\author{
WILLIAM M. MILEY, MICHAEL FRANK, and A. LEE HOXTER \\ Richard Stockton State College, Pomona, New Jersey 08240
}

\begin{abstract}
During each of the last 5 days of pregnancy, Long-Evans rats received one of the following conditions: $45 \mathrm{~min}$ of restraint and intense illumination, $3 \mathrm{~min}$ of handling, $3 \mathrm{~min}$ of restraint and $.1 \mathrm{mg}$ of androstenedione, and $3 \mathrm{~min}$ of restraint and $.1 \mathrm{ml}$ sesame oil. Half of the offspring of each group received testosterone postnatally. In adulthood, the handled group's offspring killed many pups with or without exogenous testosterone; the other offspring killed many only with testosterone. More animals that received androstenedione prenatally and testosterone postnatally killed pups than animals that received either oil or $\mathbf{4 5}$ min of restraint and intense illumination prenatally and testosterone postnatally. A subsequent manipulation found that fewer prenatally unhandled animals killed than the prenatally handled animals in this experiment. These prenatally unhandled animals required less time to retrieve pups (and more of them did so) than did any of the other groups.
\end{abstract}

Many adult social and nonsocial behaviors are affected by events during the perinatal period of development, such as sexual responses (Phoenix, Goy, Gerall, \& Young, 1959), rat-pup killing (Rosenberg, Denenberg, Zarrow, \& Frank, 1971), open-field behavior (Denenberg, Karas, Rosenberg, \& Schell, 1968), and saccharine preference (Zucker, 1969). Regarding sexual responses, male and female adult sexual behavior potentials are affected by the presence or absence of androgen during sensitive periods perinatally (Grady, Phoenix, \& Young, 1965; Phoenix et al., 1959; Ward, 1969). Genetic females exposed to perinatal androgen are defeminized and masculinized in reproductive physiology, morphology, and behavior (Phoenix et al., 1959; Ward, 1969). Genetic males that have had perinatal androgens removed are feminized and demasculinized (Grady et al., 1965; Ward, 1972a). During male differentiation in mammals, neural mechanisms develop in the presence of fetal and neonatal testicular hormones against a female trend in the last 7 days of gestation and the first 10 days after birth (Komisurak \& Diakow, 1973; Money \& Ehrhardt, 1971). When male rats are exposed to stress prenatally, they show feminized and demasculinized copulatory patterns in adulthood (Ward, 1972b). Ward (1972b) suggested that this change may occur as a result of the adrenal androgen, androstenedione (AD), which may compete successfully with testosterone (T) for brain receptor sites.

In her experiment, Ward (1972b) stressed SpragueDawley rats during the prenatal sensitive period with

We thank J. Blustein for help in the statistical analysis, and we thank the Stockton State College Research and Development Committee and L. Leitner, Dean, Social and Behavioral Sciences, for financial aid and release time to the first author for this research. restraint and intense illumination. Ward observed that the male offspring were feminized and demasculinized in behavior without detectable changes in external morphology. Since this study, Gilroy and Ward (1978) have shown that male rats exposed prenatally to supraphysiological levels of $\mathrm{AD}$ developed normal patterns of sexual behavior in adulthood. Also, Popolow and Ward (1978) have demonstrated that prenatal AD defeminized and masculinized female rats, although the effects were not as potent as T effects. Thus, Ward's (1972b) hypothesis that $\mathrm{AD}$ competes with $\mathrm{T}$ has not been confirmed, and there is evidence now that $A D$ mimics $T$ to a lesser extent. However, there is no evidence on the effects of prenatal $\mathrm{AD}$ on behavioral measures other than sexual behavior.

Regarding rat-pup killing, Rosenberg et al. (1971) found that adult male Purdue-Wistar rats will usually kill and eat rat pups, but that females rarely do. Castration of the male blocks killing, but long-term replacement therapy with testosterone propionate (TP) will maintain a normal level of killing. Rosenberg and Sherman (1974) found that postnatal TP treatment was sufficient to induce killing in ovariectomized female rats, but that prenatal TP was not necessary. However, their experimental design did not allow independent evaluation of prenatal TP. In any event, the effects of prenatal stimulation on pup killing are as yet unknown.

If a male rat does not kill rat pups, it is likely he will eventually engage in maternal behavior. Rosenblatt (1967) found that 6 or 7 days of exposure to pups were sufficient to initiate the following responses in the male rat: nest building, licking the pups, retrieving, and hovering over the pups in a nursing posture.

In the present experiment, we asked two major questions. (1) What are the effects of prenatal stress on 
pup killing and maternal behavior in the offspring of the stressed rats? (2) Can these effects be modified by TP injected postnatally? Additionally, we were interested in the effects of prenatal AD on the offsprings' pup killing and maternal behavior.

\section{METHOD}

The subjects were 109 male offspring of Long-Evans rats (Charles River) and were 91 days old at the time of behavioral tests. All animals were on ad-lib food and water throughout the experiment. The vivarium was maintained on a $12-\mathrm{h}$ reverse lightdark cycle.

When 16-day-old pregnant rats arrived in the laboratory, they were assigned randomly to one of eight experimental conditions in a 4 by 2 factorial design. Prenatally, there were four manipulations, and postnatally, there were two. During the last 5 days of gestation, one group of pregnant rats (S) received intense illumination from two $150-\mathrm{W}$ floodlights $(45.72 \mathrm{~cm}$ above the restraining apparatus) and restraint in a Plexiglas rodent restraining device for $45 \mathrm{~min}$ each day, one group (AD) received $1.0 \mathrm{mg}$ of $\Delta-4$ androstenedione in $.1 \mathrm{ml}$ sesame oil peritoneally each day, one group $(\mathrm{H})$ was handled for 3 min each day, and one group $(O)$ received $.1 \mathrm{ml}$ sesame oil peritoneally each day. Both of the prenatal injection groups received $3 \mathrm{~min}$ of restraint for injection purposes and to equate time out of cages with the handled group. Approximately $3 \mathrm{~h}$ after the litters were born, they were cross-fostered to experimentally naive mothers that had just delivered pups. Postnatally, each prenatal group was split into two groups. One of the split groups received $.5 \mathrm{mg} \mathrm{TP}$ in $.05 \mathrm{ml}$ sesame oil every other day from the 1st day after the day of birth to Day 30 and $1.0 \mathrm{mg}$ TP in $.1 \mathrm{ml}$ sesame oil from Day 60 to Day 90 (T groups). The remaining animals received $.05 \mathrm{ml}$ and $.1 \mathrm{ml}$ sesame oil on the same schedule. This TP treatment regime produces pup killing in ovariectomized rats (K. M. Rosenberg \& Sherman, 1974). Because prenatal stress may operate as a functional castration, as measured by copulatory patterns (Ward, 1972b), testicularly intact animals received chronic TP to see if it was possible to offset any prenatal stress effect (TP was not injected prenatally because of excessive abortions during pilot work). The litters remained intact until Day 23. On Day 23 , the female pups were discarded, and the male pups were reared in groups of two or three in standard laboratory cages until Day 90. On Day 90, each subject was injected appropriately and then isolated in standard laboratory cages. The animals remained in the new cages for $24 \mathrm{~h}$ prior to testing on Day 91 . On Day 91 $2 \mathrm{~h}$ past the onset of the dark phase of the light-dark cycle, each subject was tested with two 1-day-old rat pups, and latencies to kill were recorded by stopwatch. The rat pups remained in each cage for $1 \mathrm{~h}$. If a subject failed to kill on Day 91, he was tested for $1 \mathrm{~h}$ on Day 92 . Animals that failed to kill on Days 91 and 92 were tested for 8 more days $(30 \mathrm{~min} /$ day $)$ for the occurrence of pup killing or maternal behavior. The absence of killing was assigned maximum latency $(360 \mathrm{~min})$. The maternal indexes used were pup retrieval, grooming and licking, crouching over the pups, and nest building. Latency to first response was recorded for each of these indexes; the absence of a response was assigned maximum latency $(360 \mathrm{~min})$.

A subsequent group of 17 male Long-Evans rats was added to our experiment to control for the effects of handling and injections in adulthood (Group C). Their mothers were obtained from Charles River and mated in our laboratory. The 17 offspring animals were not manipulated in any way until Day 60 of life (Group C). At this time, they were split into two groups. One group of eight received the adult injection schedule of TP until Day 90, and one group of nine received the adult injection schedule of sesame oil until Day 90 . These animals then underwent behavioral testing on Day 91 , as did the other groups.

\section{RESULTS}

All latencies were transformed to common logarithms in order to account for subjects who never emitted the response. As shown in Figure 1, the mean log latency analysis revealed significant main effects for prenatal condition $[F(4,131)=7.86, p<.001]$, postnatal condition $[F(1,131)=17.71, p<.001]$, and a significant interaction $[F(4,131)=4.74, p<.001]$. TP injected postnatally decreased pup killing latencies in all of the prenatal groups (ps $<.05)$ except the $\mathrm{H}$ group and the $\mathrm{C}$ group ( $\mathrm{ps}>.05$ ). Animals in the $\mathrm{H}$ group killed pups rapidly regardless of the presence or absence of postnatal TP, and fewer than $25 \%$ of the animals $(7 / 31)$ killed at all in the $\mathrm{C}$ group. Congruent with the latency analysis, chi-square tests showed that the presence of postnatal TP increased the number of animals that killed pups in all of the prenatal groups (ps $<.01$ ) except the $\mathrm{H}$ group and the $\mathrm{C}$ group (ps $>.05$ ). Many animals killed in Group $\mathrm{H}$ regardless of the presence (6/8) or absence (7/9) of postnatal TP, and few killed in Group C whether TP was present in adulthood (3/17) or not (4/14). Group H and Group C differed from each other $(\mathrm{p}<.001)$. Also, chi-square tests showed that more animals killed in Group ADT (20/21) than in Group OT (12/19), in Group ST (9/18), or in Group CT $(3 / 17)(\mathrm{ps}<.02)$.

Pup retrieval was significantly faster for the prenatal $\mathrm{C}$ group than for all other groups (ps $<.01$ ). Congruent with the parametric analyses, chi-square tests showed more animals retrieved in this group (21 out of 31) than in any of the other prenatal groups (ps <.02). The presence or absence of TP postnatally did not produce a difference in the latency of the retrieval response $[F(1,131)=.055, p>.80]$. No other measures of maternal behavior reached significance.

\section{DISCUSSION}

Restraint and intense illumination applied prenatally completely suppressed pup killing in offspring. We did not expect the $\mathrm{AD}$ and oil conditions combined with $3 \mathrm{~min}$ of restraint prenatally to also suppress pup killing. In pilot work, we discovered that 13 out of 15 pregnant rats died when we applied Ward's (1972b) schedule or restraint and illumination for $45 \mathrm{~min}$ three times a day. In order to obtain a reasonable number of animals for experimentation, we reduced our stress procedure substantially (see Procedure, above). Even with the reduced regime, we lost $30 \%$ of our animals. Thus, we were not able to replicate Ward's stress procedure.

Handling pregnant rats during the last 5 days of gestation affected male offspring differently from animals that received the other prenatal treatments. Whether or not the male offspring of the handled animals received $T$ postnatally had no effect on their pup killing response; many offspring killed in both conditions. In effect, animals handled only behaved differently from animals that were handled and received additional stresses. Pfeifer, Rotundo, Myers, and Denenberg (1976) have shown that rats handled in infancy have a lower corticosterone response to stress at 35 days of age than do rats that recieve shock or heat stress in infancy. In our study, it is possible that 


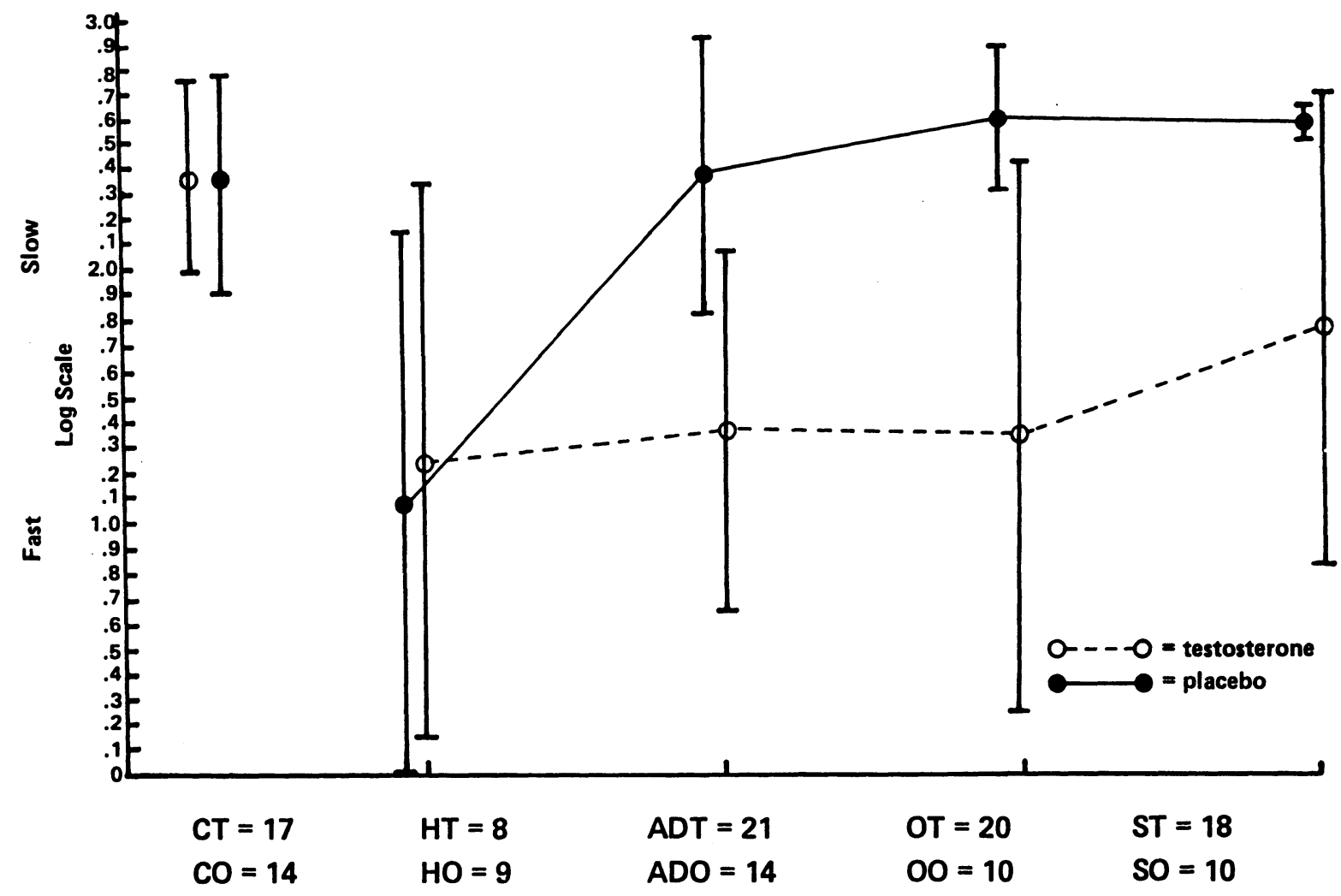

Experimental Conditions

Figure 1. Mean log latencies to pup killing and standard deviations for adult male Long-Evans rats that received four prenatal manipulations: $S=$ lights and restraints, $H=$ handling, $O=$ oil placebo, and $A D=$ androstenedione. $A$ control group (C) received no manipulation prenatally and testosterone $(T)$ or oil $(O)$ in adulthood only. The two curves represent testosterone and placebo administered immediately postnatally and in adulthood.

prenatal handling affected hormonal responses differently from the way the additional prenatal stresses did. Prenatal handling could facilitate the occurrence of species-typical responses such as pup killing in male rats. In partial support of this, fewer unhandled controls killed (Group C) than did prenatally handled rats.

Our data suggest confirmation of the hypothesis that AD mimics $T$ rather than competes with it during prenatal development. A higher number of animals that received AD prenatally killed pups than did animals that received oil, 45 min of restraints and lights, or nothing when exogeneous $T$ was provided postnatally.

The unhandled controls (Group C) in our experiment showed no effect of TP injections in adulthood; pup killing was not increased. These results suggest that pup killing is not facilitated by TP injected only in the adult period. Except for Group $\mathrm{H}$, all of the other groups received both early postnatal TP and TP injected in the adult period. Group $\mathrm{H}$ showed high levels of killing, even in the absence of postnatal TP.

Thus, prenatal handling seems to operate differently on pup killing from the other prenatal stressors, and postnatal $\mathrm{T}$ attenuates the suppressive effects of prenatal stress (as in Groups $S$ and 0 ) on this measure. However, further research is needed to show whether postnatal TP operates in this experimental design primarily in the early postnatal period or by an interaction between early postnatal and adult injections.

\section{REFERENCES}

Denenberg, V. H., Karas, G. G., Rosenberg, K. M., \& Schell, S. F. Programming life histories: An experimental design and initial results. Developmental Psychobiology, 1968, 1, 3-9.

GILroy, A. F., \& WARD, I. L. Effects of perinatal androstenedione on sexual differentiation in male rats. Behavioral Biology, 1978, 23, 243-248.

Grady, K. L., Phoenix, C. H., \& Young, W. C. Role of the developing rat testis in differentiation of the neural tissues mediating mating behavior. Journal of Comparative and Physiological Psychology, 1965, 59, 176-182.

Komisurak, B. R., \& Diakow, C. Lordosis reflex intensity in rats in relation to the estrous cycle, ovariectomy, estrogen administration and mating behavior. Endocrinology, 1973, 93, 548-557.

Money, J., \& Ehrhardt, A. A. Fetal hormones and the brain: Effect on sexual dimorphism of behavior-A review. Archives of Sexual Behavior, 1971, 1, 241-263.

Pfeifer, W. D., Rotundo, R., Myers, M., \& Denenberg, V. Stimulation in infancy: Unique effects of handling. Physiology \& Behavior, 1976, 17, 781 .

Phoenix, C. H., Goy, R. W., Gerall, A. A., \& Young, W. C. Organizing action of prenatally administered testosterone 
propionate on the tissues mediating mating behavior in the female guinea pig. Endocrinology, 1959, 65, 369-382.

Popolow, H. B., \& WARD, I. L. Effects of perinatal androstenedione on sexual differentiation in female rats. Journal of Comparative and Physiological Psychology, 1978, 92, 13-21.

Rosenberg, K. M., Denenberg, V. H., Zarrow, M. X., \& FrANK, B. L. Effects of neonatal castration and testosterone on the rat's pup-killing behavior. Physiology \& Behavior, 1971, 7, 363-368.

Rosenberg, K. M., \& Sherman, G. F. Testosterone induced pup-killing behavior in the ovariectomized female rat. Physiology \& Behavior, 1974, 13, 697-699.

RosenBlatT, J. S. Nonhormonal basis of maternal behavior in the rat. Science, 1967, 156, 1512-1514.
WARD, I. L. Differential effect of pre- and postnatal androgen on the sexual behavior of intact and spayed female rats. Hormone and Behavior, 1969, 1, 25-36.

WARD, I. L. Female sexual behavior in male rats treated prenatally with an anti-androgen. Physiology \& Behavior, 1972, 8, 53-56. (a)

Ward, I. L. Prenatal stress feminizes and demasculinizes the behavior of males. Science, 1972, 175, 82-84. (b)

ZUCKER, J. Hormonal determinants of sex differences in saccharine preference, food intake, and body weight. Physiology \& Behavior, 1969, 4, 595-602.

(Received for publication January 30, 1981.) 